\title{
Diagnostic and Prognostic Particularities of the Implications of the Presence of Tumor Necrosis Factor Alpha in Patients with Periodontal Disease
}

\author{
Yero leremie Lia Maria, Lazăr Luminița*, Ciurba Adriana \\ University of Medicine and Pharmacy of Tirgu Mures, Romania
}

Periodontal disease can have significant effects by increasing the circulating levels of TNF- $\alpha$, therefore its prevention and treatment is important in maintaining the overall health of the body. Objective: The aim of our research was to assess the differences in the salivary concentration of TNF- $\alpha$ between patients with periodontal disease and those free of the disease and to studz whether it can represent an indicator of the evolution of periodontal disease. We also aimed to assess the practical applicability of the method for the determination of this cytokine in the saliva. Materials and methods: Our study included two groups of subjects, the first group consisting in patients diagnosed with periodontal disease, while the control group included subjects free of periodontal disease. TNF- $\alpha$ concentration was determined with the ELISA test for human TNF- $\alpha$ and the results were expressed in $\mathrm{pg} / \mathrm{mL}$. The data were statistically processed with GraphPad software and the statistical nonparametric Mann-Whitney test was applied. Results: We observe nearly double values of the TNF- $\alpha$ salivary level in the group of patients suffering from periodontal disease compared to the subjects free of periodontal disease, which allows us to notice that saliva analysis is a useful and safely enough method for the diagnosis and follow-up in the development of periodontal disease. Conclusion: The salivary level of TNF- $\alpha$ in patients with periodontal disease is not only an indicator of periodontal disease progression, but also a reflection of the pathogen potential that periodontal disease may have on the overall health of the body.

Keywords: TNF- $\alpha$, salivary concentration, periodontal disease

Received: 7 December 2014 / Accepted: 22 December 2014

\section{Introduction}

Tumor necrosis factor-alpha (TNF- $\alpha)$ is a biomarker involved in systemic inflammation which belongs to a group of cytokines that stimulate the acute phase reaction. The primary role of TNF- $\alpha$ is to adjust the immune cells, however this cytokine is also capable to induce inflammation and cell death via apoptosis and to inhibit carcinogenesis and viral replication.

TNF- $\alpha$ is produced mainly by macrophages, but can be released by a wide variety of other cell types: lymphocytes, monocytes, endothelial cells, cardiacmyocytes, adipose tissue, fibroblasts, and nerve tissue.

The local increase in TNF- $\alpha$ concentration causes the appearance of inflammation, therefore circulating TNFalpha levels in patients with chronic marginal periodontitis is significantly higher compared to healthy subjects. After the commencement of the initial therapy, the serum concentration of the cytokine may be reduced significantly [1].

Periodontal disease can have significant effects by increasing the circulating levels of TNF- $\alpha$, therefore its prevention and treatment is important in maintaining the overall health of the body [2].

* Correspondence to: Luminita Lazăr

E-mail: luminita.lazar@umftgm.ro

\section{Objective}

The aim of our research was to assess the differences of TNF- $\alpha$ salivary concentrations in patients with periodontal disease compared with subjects free of the disease, and to study whether this could be an indicator of the evolution of periodontal disease. We also aimed to assess the practical applicability of the method used for the determination of this cytokine in the saliva.

\section{Materials and methods}

Our study included two groups of subjects. The study group included 15 patients diagnosed with moderate or severe periodontal disease, while the control group consists of 15 subjects free of periodontal disease. The diagnosis of periodontal disease was established on the basis of clinical investigations, laboratory and imagistic tests.

In each subject of the two groups we collected $10 \mathrm{~mL}$ of unstimulated saliva expectorated into sterile centrifuge tubes. After centrifugating the sample of saliva for 3 minutes at $8000 / \mathrm{g}$, the clear decanted saliva was filtered through a low protein binding membrane. The separation into a polythene container and the samples marked for identification were refrigerated until examination.

TNF- $\alpha$ concentration was determined with the ELISA test for human TNF- $\alpha$, according to the manufacturer's instructions, and the results were expressed in $\mathrm{pg} / \mathrm{mL}$.

The data were statistically processed with GraphPad software to determine the presence of a significant difference 
in concentration between the two investigated groups. For this purpose, the statistical non-parametric Mann-Whitney test was applied. Values of $\mathrm{p}<0.05$ were considered statistically significant.

\section{Results}

The determined values of the TNF- $\alpha$ in the saliva of the two groups of subjects are presented in table 1.

The Mann-Whitney statistical test was used to verify the presence of any significant differences of the median TNF- $\alpha$ concentrations in the two groups.

Table I. Mean values $(\mathrm{pg} / \mathrm{mL})$ and statistical data for TNF- $\alpha$ in the saliva

\begin{tabular}{lcc}
\hline Parameter & $\begin{array}{c}\text { TNF- } \alpha \\
\text { Control group }\end{array}$ & $\begin{array}{c}\text { TNF- } \alpha \\
\text { Patients }\end{array}$ \\
\hline Mean value: & 1.462 & 2.657 \\
Number of determinations: & 15 & 15 \\
Standard deviation: & 0.1003 & 0.2215 \\
Standard error: & 0.02894 & 0.05719 \\
Minimum: & 1.290 & 2.000 \\
Maximum: & 1.620 & 2.900 \\
Median: & 1.460 & 2.750 \\
Inf.I 95\% confidence interval: & 1.398 & 2.534 \\
Sup. 95\% confidence interval & 1.525 & 2.779 \\
\hline
\end{tabular}

The $p$ value $<0.0001$, considered extremely significant, indicates that there was a difference in the concentration of TNF- $\alpha$ in patients with periodontal disease as compared with the control group.

\section{Discussions}

Our study indicated nearly double values of the TNF- $\alpha$ salivary level in the group of patients suffering from periodontal disease compared to the subjects free of periodontal disease.

These results are similar to those published by Rai [2], who found TNF- $\alpha$ salivary values in patients with periodontal disease around $2.83 \mathrm{pg} / \mathrm{mL}$, compared to $1.45 \mathrm{pg} /$ $\mathrm{mL}$ in subjects free of periodontal disease.

Prolonged or permanent presence of high concentrations of TNF- $\alpha$ in the saliva may contribute to the development of periodontal disease. As a diagnostic fluid, saliva is still insufficiently used in everyday practice. It offers advantages over serum because its collection is noninvasive and requires no special training on the side of the clinician. Furthermore, saliva analysis showed of biochemical and immunological variation comparable to those in blood evaluated as routine practice $[3,4]$.

Our data suggest an important role of high TNF- $\alpha$ concentrations in perpetuating pathological phenomena characteristic of periodontal disease. High TNF- $\alpha$ serum levels are maintained by inflammatory and infectious processes associated with chronic periodontitis $[5,6]$.
Establishment of initial periodontal therapy by mechanical treatment leads to improved clinical status and TNF- $\alpha$ values lower than those recorded on initial examination [7]. Yun et al. [8] observed that high serum levels of TNF- $\alpha$ detected in patients with chronic periodontitis are significantly reduced after periodontal surgery.

Determining TNF- $\alpha$ values in the peri-implant crevicular fluid could represent an important feature in early detection of the presence of lesions that are not clinically apparent when monitoring the osseointegration process of the implant [9-11]. Mechanical peri-implant therapy leads to reduced TNF- $\alpha$ levels in the crevicular fluid associated with improved clinical parameters $[12,13]$.

The administration of drugs with anti-TNF- $\alpha$ effect may lead to low cytokine levels in the periodontal tissue and in the crevicular fluid, with beneficial effects in suppressing periodontal disease [14-16].

\section{Conclusion}

Our results regarding the presence of TNF- $\alpha$ in total saliva prompt us to notice that saliva analysis is a useful and safely enough method for the diagnosis and follow-up in the development of periodontal disease.

Modified values of the salivary levels of this cytokine in patients with periodontal disease, significantly higher than those in subjects free of periodontal disease, is not only an indicator of periodontal disease progression, but also a reflection of the pathogen potential that periodontal disease may have on the overall health of the body.

\section{References}

1. Wang Y., Yang PS, Oi XM, Ren JM, Ge SH.: Change of circulating TNFalpha in patients with advanced periodontitis before and after periodontal initial therapy, Shanghai Kou Qiang Yi Xue, 2003 apr; 12(2):85-87.

2. Rai B. Salivary Levels of Tumor Necrosis Factor-Alpha in 201 Periodontitis, Advances in Medical and Dental Sciences, 2008;2(2):40-41.

3. Dağ A, Firat ET, Kadiroğlu AK, Kale E, Yilmaz ME. Significance of elevated gingival crevicular fluid tumor necrosis factor-alpha and interleukin-8 levels in chronic hemodialysis patients with periodontal disease.J Periodontal Res. 2010;45(4):445-50.

4. Gürsoy UK, Yildiz Çiftlikli S, Könönen E, Gürsoy M, Doğan B. Salivary II-17 and Tnf-A in Relation to Periodontitis and Glycemic Status in Type 2 Diabetes Mellitus. J Diabetes 2014, doi: 10.1111/1753-0407.12228. [Epub ahead of print]

5. Engebretson S, Chertog R, Nichols A, Hey-Hadavi J, Celenti R, Grbic $\mathrm{J}$. Plasma levels of tumour necrosis factor-alpha in patients with chronic periodontitis and type 2 diabetes. J ClinPeriodontol. 2007;34(1):18-24.

6. Singh P, Gupta ND, Bey A, Khan S. Salivary TNF-alpha: A potential marker of periodontal destruction. J Indian SocPeriodontol. 2014;18(3):306-310.

7. Erdemir EO, Duran I, Haliloglu S. Effects of smoking on clinical parameters and the gingival crevicular fluid levels of IL-6 and TNF-alpha in patients with chronic periodontitis. J Clin Periodontol. 2004;31(2):99-104.

8. Yun F, Firkova El, Xun H, Jun-Qi L. Effects of surgical periodontal therapy on serum levels of TNF-alpha in patients with chronic periodontitis. Folia Med (Plovdiv). 2007;49(1-2):37-40.

9. EG, Tsalikis L. A review on peri-implant crevicular fluid assays potential in monitoring and predicting peri-implant tissue responses. J IntAcadPeriodontol. 2002;4(2):49-59.

10. Petković AB, Matić SM, Stamatović NV, Vojvodić DV, Todorović TM, Lazić ZR, Kozomara RJ. Proinflammatory cytokines (IL-1beta and TNF-alpha) and chemokines (IL-8 and MIP-1alpha) as markers of peri-implant tissue condition.Int J Oral Maxillofac Surg. 2010;39(5):478-485.

11. Javed F, Al-Hezaimi K, Salameh Z, Almas K, Romanos GE.Proinflammatory cytokines in the crevicular fluid of patients with peri-implantitis. Cytokine. 
2011;53(1):8-12.

12. Duarte PM, de Mendonça AC, Máximo MB, Santos VR, Bastos MF, Nociti $\mathrm{FH}$.Effect of anti-infective mechanical therapy on clinical parameters and cytokine levels in human peri-implant diseases.J Periodontol. 2009;80(2):234-243

13. de Mendonça AC, Santos VR, César-Neto JB, Duarte PM.Tumor necrosis factor-alpha levels after surgical anti-infective mechanical therapy for periimplantitis: a 12-month follow-up.J Periodontol. 2009;80(4):693-699.

14. Mayer Y, Balbir-Gurman A, Machtei EE.Anti-tumor necrosis factor-alpha therapy and periodontal parameters in patients with rheumatoid arthritis.J
Periodontol. 2009;80(9):1414-1420.

15. Mayer Y1, Elimelech R, Balbir-Gurman A, Braun-Moscovici Y, Machtei EE.Periodontal condition of patients with autoimmune diseases and the effect of anti-tumor necrosis factor- $\alpha$ therapy.J Periodontol. 2013;84(2):136-142.

16. Cetinkaya B, Guzeldemir E, Ogus E, Bulut S.Proinflammatory and antiinflammatory cytokines in gingival crevicular fluid and serum of patients with rheumatoid arthritis and patients with chronic periodontitis.J Periodontol. 2013;84(1):84-93. 